\title{
CUSTO DE PRODUÇÃO E ANÁLISE ECONÔMICA DE ABÓBORA EM TANGARÁ DA SERRA-MT
}

\author{
RAMBO, José Roberto ${ }^{1}$ \\ LAFORGA, Gilmar ${ }^{1}$ \\ SANTI, Adalberto ${ }^{1}$
}

RESUMO: A cultura da abóbora é uma das principais atividades agrícolas da horticultura, possui significativa importância socioeconômica e alimentar pela geração de emprego e renda na agricultura familiar. O objetivo deste trabalho foi estimar os custos de produção e proceder à análise econômica do cultivo da abóbora por agricultores familiares de Tangará da Serra-MT, conforme metodologia proposta por Martin et al. (1998). Verificou-se que o sistema de plantio de abóbora local apresentou por hectare: Produção de $2.400 \mathrm{~kg}$, Custo Operacional Total de $\mathrm{R} \$ 1.262,10$, Receita Bruta que apresenta variação de $\mathrm{R} \$ 2.400,00$ a $\mathrm{R} \$ 2.592,00$, dependente do valor de comercialização do produto que variou de $\mathrm{R} \$ 1,00$ a $\mathrm{R} \$ 1,08$ o $\mathrm{kg}$. Os índices de lucratividade variam de 47,41\% a $51,31 \%$. A atividade da aboboreira possui bom potencial de geração de renda a agricultores familiares.

Palavras-chave: Assentamento. Comercialização. Lucratividade. Agricultura Familiar

SUMMARY: The pumpkin culture is one of the main agricultural activities is horticulture, having significant socioeconomic importance for the generation of employment and income in family farming. The aim of this study was to estimate the costs of production of pumpkin in Tangará da Serra-MT. For family farmers, as well as to make an economic analysis of it following the methodology proposed by Martin et al. (1998). It was found that the conventional system of pumpkin presented by hectare: production of $2400 \mathrm{~kg}$, total operating cost of $R \$ 1.262,10$, gros revenue from $\mathrm{R} \$ 2,400.00$ to $\mathrm{R} \$ 2,592.00$ (depending on the market value of the product, ranging from $\mathrm{R} \$ 1,00$ to $\mathrm{R} \$ 1,08 \mathrm{a} \mathrm{kg}$ ) and profitability index range from $47,41 \%$ to $51,31 \%$. The activity of pumpkin has good potential to income generation for family farmers.

Keywords: Stellement. Marketing. Profitability. Family farm

\section{INTRODUÇÃO}

As cucurbitáceas compõem a segunda família de maior importância econômica entre as hortaliças produzidas no Brasil (RAMOS et al., 2010). Os cultivos agrícolas de culturas da família, tais como abóbora (Cucurbita moschata), chuchu (Sechium edule), maxixe (Cucumisanguria), melancia (Citrulluslanatus), melão (Cucumis melo), moranga (Cucurbita maxima) e pepino (Cucumissativus), são de ampla importância social, econômica e alimentar (SOUZA et al., 2014, RESENDE; BORGES; GONÇALVES, 2013). Para Amaro et al. (2014), especificamente abóboras e morangas ocupam o $7^{\circ}$ lugar em volume entre as hortaliças mais cultivadas no Brasil.

Resende, Borges e Gonçalves (2013) estimam que no ano de 2010 a produção mundial em escala comercial foi de aproximadamente 22,4 milhões de toneladas de abóbora, cultivadas em área de 1,67 milhão de hectares, com uma produtividade média de 13,4 t.ha ${ }^{-1}$. Para o Brasil, os dados referentes à cultura são escassos, e as informações disponíveis para o ano de 2006 (IBGE, 2016) registram área colhida de 88.197 hectares, com 384.912 toneladas produzidas e produtividade média de 4,4 t.ha ${ }^{-1}$.

\footnotetext{
${ }^{1}$ Curso de Agronomia - Faculdade de Ciências Agrárias, Biológicas, Engenharia e da Saúde - Universidade do Estado de Mato Grosso
} 
A abóbora é cultivada em mais de 127 mil estabelecimentos agropecuários, cultivo este que ocorre normalmente em pequenas propriedades rurais, sendo importante na diversificação da produção da propriedade familiar (RAMOS et al., 2010). No estado de Mato Grosso, também para o ano de 2006, em 1.677 estabelecimentos agropecuários foram produzidas 3.253 toneladas de abóbora, em uma área colhida de 1.489 hectares e produtividade média de 2,18 t.ha ${ }^{-1}$; pode-se afirmar que a participação percentual estadual é de somente 1\% em relação aos números nacionais (IBGE, 2016).

O cultivo de cucurbitáceas, no caso as abóboras, apresenta importante valor econômico e alimentar e também grande importância social na geração de empregos diretos e indiretos, pois demanda grande quantidade de mão de obra em todas as fases de produção, desde a semeadura até a comercialização (MARCELINO; MARCELINO, 2012).

A produção de abóbora pode ser considerada uma alternativa viável na ocupação de mão de obra e renda para os agricultores familiares, segmento que corresponde a 84,4\% dos estabelecimentos agropecuários brasileiros (KAGEYAMA, BERGAMASCO; OLIVEIRA, 2013). É importante ressaltar que, nos últimos anos, o segmento agrícola familiar vem passando por significativas transformações, em especial, no marco do impulso das políticas públicas (BECKER e ANJOS, 2010).

O Programa de Aquisição de Alimentos da Agricultura Familiar (PAA) criado pela Lei $\mathrm{n}^{\circ}$. 10.696/2003 é parte da política de fortalecimento do segmento, direcionada especificamente à aquisição, pelo governo, de grupos, cooperativas ou associações, de alimentos produzidos pelo segmento familiar (BRASIL, 2003). Segundo o Ministério da Cidadania - MDS (2019), o PAA tem como finalidade: i) promover o acesso à alimentação e ii) incentivar a agricultura familiar.

Os custos de produção da cultura da abóbora variam entre as diferentes categoriais de produtores e níveis tecnológicos adotados. Segundo a CONAB (2010), na estimativa dos custos de produção de uma atividade, deve-se levar em conta a alocação dos recursos produtivos e o conhecimento de seus preços, fatores estes que podem variar de produtor para produtor, ou seja, os custos de produção podem variar de local para local.

Neste sentido, o objetivo deste trabalho foi analisar os custos de produção da abóbora em Tangará da Serra-MT, com a caracterização da estimativa dos custos e da receita da aboboreira, comercializada para dois tipos de mercados pelos agricultores familiares: a) mercado tradicional - comercialização realizada pelo produtor com intermediário ou por venda direta ao consumidor final e b) mercado institucional via PAA - comercialização realizada pelo produtor com a CONAB (Companhia Nacional de Abastecimento) por intermédio da Coopervida (Cooperativa dos Produtores da Agricultura Familiar de Tangará da Serra e Região) pela CPR MT/2014/02/0064.

\section{MATERIAL E MÉTODO}

A pesquisa desenvolveu-se em novembro de 2015, no Assentamento Antônio Conselheiro em Tangará da Serra, com a aplicação de formulário de perguntas abertas e fechadas a um agricultor familiar; as questões foram propostas, bem como as respostas anotadas, pelo entrevistador no contato face a face com o entrevistado (PÁDUA, 2004).

A propriedade pesquisada conta com mão de obra familiar efetiva de quatro pessoas e possui experiência no cultivo de abóbora (Cucurbita moschata) em sistema de plantio convencional manual intensivo em trabalho.

O cultivo de abóbora foi realizado em abril de 2015 sobre área que anteriormente era ocupada com culturas anuais; o(a) agricultor(a) familiar identificou a abóbora da variedade Mini Paulista; onde as sementes foram adquiridas em casa agropecuária na sede do município, e o espaçamento utilizado foi de 4 
x 4 metros, com 625 covas por hectare e produção média por hectare de 2.400 quilogramas. A descrição do sistema de produção, relatada pelo agricultor, faz utilização de insumos como sementes, calcário, fertilizantes e inseticida e ocorre em condições de sequeiro com a colheita sendo realizada em agosto de 2015.

A metodologia do cálculo do custo de produção foi a definida por Matsunaga et al. (1976) acerca do Custo Operacional Total (COT), seguindo a descrição feita por Martin et al. (1998). A estrutura do Custo Operacional Total de produção da atividade focalizada é formada pelos seguintes componentes:

A) Despesas com Operações Mecanizadas - são os custos com as operações agrícolas utilizadas no sistema produtivo, representados pelas despesas do produtor em reais $\left(\mathrm{R} \$ . \mathrm{ha}^{-1}\right)$ com hora/máquina (hm) para a realização da gradagem (cobrado $\mathrm{R} \$ 100,00$ por hora/máquina por prestador deste serviço) da área no preparo do solo para o cultivo de abóbora;

B) Despesas com Operações Manuais - constituem as despesas com atividades manuais (cobrado $\mathrm{R} \$ 80,00$ pelo trabalho homem/dia (hd) por prestador deste serviço, mesmo que o serviço tenha sido realizado pelo próprio agricultor ou familiar) realizadas por hectare: i) despesas com preparo da área, e plantio das sementes na área em reais $(\mathrm{R} \$)$ por homem/dia (hd), ii) tratos culturais em reais (R\$) por homem/dia (hd), na abertura das covas, na limpeza do cultivo, na aplicação de fertilizantes de base e de cobertura e na aplicação de inseticida no controle de insetos, iii) colheita e encaixamento das abóboras em reais $(\mathrm{R} \$)$ por homem/dia (hd);

C) Despesas com Material Consumido - são as despesas relativas à quantidade de cada material consumido na atividade multiplicada pelo preço de aquisição: i) sementes de abóbora, ii) fertilizantes de base e de cobertura e iii) produtos fitossanitários - inseticida;

D) Custo Operacional Efetivo (COE) - constitui o somatório das despesas A, B e C e representa o desembolso, por hectare, realizado pelo agricultor para produzir determinada quantidade de produto;

E) Outros custos operacionais - correspondem à parte das despesas gerais da empresa agrícola e podem ser estimados sobre 5\% do percentual do COE (MARTIN et al., 1998);

F) Custo Operacional Total (COT) - é o somatório do COE e dos outros custos operacionais, representando aquele custo em que o agricultor familiar incorre no curto prazo para produzir e para repor outros gastos, por hectare, e continuar produzindo.

Neste estudo não foram levados em consideração os custos de oportunidade da atividade produtiva relativos à remuneração do capital fixo em terra, instalações e máquinas, que se somados ao COT corresponderiam ao Custo Total de Produção (CTP).

Já para a análise econômica da atividade, foram determinados os seguintes indicadores econômicos, conforme descrevem Martin et al., (1998):

A) Receita Bruta (RB): trata-se da receita esperada para a atividade (definida a partir dos preços de comercialização praticados pelo agricultor familiar na produção de abóbora tanto para o mercado tradicional, quanto para com o institucional via PAA) e o respectivo rendimento por hectare, por um preço de venda pré-definido (produtividade da abóbora em kg.ha ${ }^{-1} \mathrm{x}$ preço de venda do produto em $\mathrm{R} \$ . \mathrm{kg}^{-1}$ );

B) Lucro Operacional (LO): é constituído da diferença entre os valores da receita bruta (RB) e o custo operacional total (COT) por hectare de abóbora ( $\mathrm{LO}=\mathrm{RB}-\mathrm{COT})$;

C) Índice de Lucratividade (IL): demonstra a relação entre o $\mathrm{LO}$ e a RB, em percentagem (IL = (LO/RB) x 100), sendo uma medida que mostra a taxa disponível (\%) de receita da atividade após o pagamento de todos os custos operacionais;

D) Margem Bruta (MB): indica a margem de relação da RB ao COT $(\mathrm{MB}=(\mathrm{RB}-\mathrm{COT}) / \mathrm{COT} \mathrm{x}$ 100)), isto é, caracteriza qual é a disponibilidade (\%) para cobrir os demais custos fixos, o risco e a capacidade empresarial do produtor; 
E) Ponto de Nivelamento (PN Produção): permite visualizar, dados os custos de produção da abóbora e o preço de venda (pv) do produto, qual a quantidade deste produto necessária para pagar os custos operacionais totais (Produção $=\mathrm{COT} / \mathrm{pv}$ );

F) Ponto de Nivelamento (PN Preço): permite visualizar, dados os custos operacionais totais da abóbora e a produtividade (p) do sistema produtivo, qual o preço de comercialização da abóbora necessário para pagar os custos de produção (Preço = COT/p).

\section{RESULTADO E DISCUSSÃO}

A estimativa de custo operacional total (COT) de produção de abóbora, com o custo operacional efetivo (COE) e suas despesas com operações manuais e com os outros custos operacionais para a cultura, é detalhada na Tabela 1.

Enquanto despesas com operações mecanizadas (gradagem) teve-se desembolso por parte do agricultor familiar de $\mathrm{R} \$ 200,00$ por hectare, que corresponde a 15,85\% do COT da cultura, para preparar a área para o cultivo de abóbora.

No desenvolver das operações manuais, o agricultor familiar teve despesas de $\mathrm{R} \$ 616,00$ por hectare, equivalente a $48,81 \%$ do COT da produção de abóbora. Sendo as operações de colheita e encaixe as que demandam mais mão de obra, tanto que a despesas com estas operações foram de $R \$ 240,00$, constituindo-se em 38,96\% das despesas com operações manuais. As operações de capinas e de semeadura, tiveram despesas de $\mathrm{R} \$ 80,00$ cada atividade, sendo $25,98 \%$ das despesas com operações manuais. Logo em seguida, a operação de aplicação de inseticida, foi a que demandou mais despesas por parte do agricultor familiar, sendo que o mesmo com as operações, teve despesas de R $\$ 76,00$, que representam $12,34 \%$ das despesas com operações manuais. Com abertura de covas, para o posterior plantio da abóbora, a despesa foi de $\mathrm{R} \$ 60,00$, correspondente a 9,74\% das despesas com operações manuais. Ainda como despesas com operações manuais, teve-se as atividades de incorporação de fertilizantes e a adubação de cobertura, que consumiram $\mathrm{R} \$ 20,00$ cada atividade, equivalentes a $6,49 \%$ das despesas com operações manuais.

As despesas com os materiais consumidos (sementes, fertilizantes, corretivos e inseticidas) na produção de abóbora foram de $\mathrm{R} \$ 386,00$ por hectare e representaram 30,58\% do COT. Os fertilizantes utilizados na implantação da abóbora, como o esterco bovino e o superfosfato simples, somados aos de cobertura (ácido bórico e cloreto de potássio) e corretivos (calcário), corresponderam a 67,62\% deste total. Já a semente ( $\mathrm{R} \$ 80,00)$ constituiu $20,72 \%$ das despesas com materiais consumidos. A despesa com inseticida $(\mathrm{R} \$ 45,00)$ representou $11,65 \%$ das despesas de materiais consumidos, porém percebeu-se que não houve tratamentos fitossanitários para o controle de doenças, fator que comprometeu em parte a produção de abóbora.

O COE de um hectare de abóbora em Tangará da Serra-MT foi de R $\$ 1.202,00 /$ ha. Somando-se o COE obtido neste trabalho ao valor de $\mathrm{R} \$ 60,10$ de outros custos operacionais, o COT de um hectare de abóbora foi estimado em $\mathrm{R} \$ 1.262,10 / \mathrm{ha}$. 
Tabela 1. Estimativa de custo operacional total (COT) de produção de abóbora, para um hectare, no Assentamento Antônio Conselheiro em Tangará da Serra-MT, 2015.

\begin{tabular}{|c|c|c|c|}
\hline Descriçãa & $\begin{array}{c}\text { Valor Unitário } \\
(\mathbf{R} \$)\end{array}$ & Quantidade & $\begin{array}{c}\text { Valor Total } \\
(\mathbf{R} \$)\end{array}$ \\
\hline \multicolumn{4}{|c|}{ 1. Despesas com Operações Mecanizadas } \\
\hline Gradagem (hm) & 100,00 & 2,0 & 200,00 \\
\hline \multicolumn{3}{|l|}{ Subtotal 1} & 200,00 \\
\hline \multicolumn{4}{|l|}{ 2. Despesas com Operações Manuais } \\
\hline \multicolumn{4}{|l|}{ 2.1. Implantação } \\
\hline Correção do solo (hd) & 80,00 & 0,50 & 40,00 \\
\hline Coveamento (hd) & 80,00 & 0,75 & 60,00 \\
\hline Incorporação de fertilizantes (hd) & 80,00 & 0,25 & 20,00 \\
\hline Semeadura (hd) & 80,00 & 1 & 80,00 \\
\hline \multicolumn{4}{|l|}{ 2.2. Tratos culturais } \\
\hline Capinas (hd) & 80,00 & 1,0 & 80,00 \\
\hline Adubação de cobertura(hd) & 80,00 & 0,25 & 20,00 \\
\hline Aplicação de inseticida(hd) & 80,00 & 0,95 & 76,00 \\
\hline \multicolumn{4}{|l|}{ 2.3. Colheita } \\
\hline Colheita e encaixe (hd) & 80,00 & 3,0 & 240,00 \\
\hline \multicolumn{3}{|l|}{ Subtotal 2} & 616,00 \\
\hline \multicolumn{4}{|c|}{ 3. Despesas com Materiais Consumidos } \\
\hline \multicolumn{4}{|l|}{ 3.1 Sementes } \\
\hline Semente (pct) & 80,00 & 1,0 & 80,00 \\
\hline \multicolumn{4}{|l|}{ 3.2. Fertilizantes } \\
\hline Esterco bovino $(\mathrm{t})$ & 120,00 & 0,62 & 75,00 \\
\hline Cloreto de potássio $(1 \mathrm{x})(\mathrm{kg})$ & 3,00 & 10,0 & 30,00 \\
\hline Superfosfato simples $(1 \mathrm{x})(\mathrm{kg})$ & 1,20 & 45,0 & 54,00 \\
\hline Ácido bórico $(\mathrm{kg})$ & 10,00 & 3,2 & 32,00 \\
\hline Calcário (t) & 35,00 & 2,0 & 70,00 \\
\hline \multicolumn{4}{|l|}{ 3.3. Fitossanitários } \\
\hline Inseticida $(1 \mathrm{x})(\mathrm{l})$ & 180,00 & 0,25 & 45,00 \\
\hline \multicolumn{3}{|l|}{ Subtotal 3} & 386,00 \\
\hline \multicolumn{4}{|l|}{ 4. Custo Operacional Efetivo (COE) } \\
\hline \multicolumn{3}{|l|}{ Subtotal $1+$ Subtotal $2+$ Subtotal 3} & $1.202,00$ \\
\hline \multicolumn{4}{|l|}{ 5. Outros Custos Operacionais } \\
\hline \multicolumn{3}{|l|}{ Outras Despesas (5\% do COE) } & 60,10 \\
\hline \multicolumn{4}{|l|}{ 6. Custo Operacional Total (COT) } \\
\hline \multicolumn{3}{|l|}{ COE + Outros Custos Operacionais } & $1.262,10$ \\
\hline
\end{tabular}

Legenda: hd - homem dia, $\mathrm{hm}$ - hora máquina, pct - pacote, $\mathrm{t}$ - tonelada e $\mathrm{l}$ - litro.

Fonte: Elaboração dos autores.

Fachini et al. (2009), apuraram que os fertilizantes foram responsáveis por $47 \%$ do COT da cultura da abóbora, a aquisição das sementes correspondeu a 1\% do COT e a participação de corretivos, fungicidas e inseticidas somados foi menor que 1\% do COT. Para os autores, os custos com mão de obra corresponderam a 33\% do COT da cultura da abóbora. Já para Araújo e Correia (2010), as operações mecanizadas corresponderam a $14,31 \%$ do $\mathrm{COE}$, as despesas com operações manuais representaram $47,44 \%$ do COE, com fertilizantes, o custo foi de $20,36 \%$ do COE, sementes representaram $2,17 \%$ do COE, o espalhante adesivo, inseticidas e fungicidas atingiram 4,5\% do COE, e a água foi responsável por despesas que corresponderam a 12,24\% do COE no cultivo de abóbora.

De modo geral, se percebe que despesas com operações manuais representam proporcionalmente importante fator na determinação dos custos de produção de abóbora, variando de $33 \%$ a $48,81 \%$ do COT 
da produção de abóbora. Logo em seguida, materiais consumidos, correspondem a despesas que variam de 30,58\% a mais de 50\% do COT. Em contraposição, o item operações mecanizadas, é o que apresenta menor participação no custos de produção de abóbora, participando somente de até $15,85 \%$ do COT. Ou seja, percebe-se que o nível tecnológico adotado, influencia na participação percentual de insumos, operações mecanizadas e operações manuais da produção de abóbora.

Na comercialização de abóbora, a receita bruta do agricultor familiar, como se observa na Tabela 2 , pode variar de $\mathrm{R} \$ 2.400,00 /$ ha a $\mathrm{R} \$ 2.592,00 / \mathrm{ha}$, em função do tipo de comercialização realizado. Como para os dois tipos de comercialização o COT e também a produtividade obtida são iguais, o preço de nivelamento, isto é, o preço mínimo necessário para pagar o COT, foi de $\mathrm{R} \$ 0,53 / \mathrm{kg}$, independentemente do tipo de comercialização.

Tabela 2. Estimativas de produção, preços e indicadores econômicos da produção de abóbora, para um hectare, no Assentamento Antônio Conselheiro em Tangará da Serra-MT, 2015.

\begin{tabular}{|c|c|c|}
\hline Tipo de Comercialização & Tradicional & Institucional \\
\hline Preço Médio $\left(\mathrm{R} \$ . \mathrm{kg}^{-1}\right)$ & 1,00 & 1,08 \\
\hline Produtividade $\left(\mathrm{kg} \mathrm{ha}^{-1}\right)$ & 2.400 & 2.400 \\
\hline Receita Bruta $\left(\mathrm{R} \$\right.$. ha $\left.^{-1}\right)$ & $2.400,00$ & $2.592,00$ \\
\hline $\operatorname{COT}\left(\mathrm{R} \$ \mathrm{ha}^{-1}\right)$ & $1.262,10$ & $1.262,10$ \\
\hline Lucro Operacional (LO) $\left(\mathrm{R} \$ . \mathrm{ha}^{-1}\right)$ & $1.137,90$ & $1.329,90$ \\
\hline Índice de Lucratividade (IL) (\%) & 47,41 & 51,31 \\
\hline Margem Bruta (\%) & 90,16 & 105,37 \\
\hline PN Produção $\left(\mathrm{kg} \cdot \mathrm{ha}^{-1}\right)$ & 1.262 & 1.169 \\
\hline PN Preço $\left(\mathrm{R} \$ . \mathrm{kg}^{-1}\right)$ & 0,53 & 0,53 \\
\hline
\end{tabular}

Fonte: Elaboração dos autores.

Para o mercado tradicional de comercialização de abóbora do agricultor familiar, o preço médio pago pelos compradores é de $\mathrm{R} \$ 1,00$ por quilograma de abóbora; tem-se, portanto receita bruta de $\mathrm{R} \$ 2.400,00 /$ ha. Assim sendo, o lucro operacional seria de $\mathrm{R} \$ 1.137,90 /$ ha, e para o produtor de abóbora de Tangará da Serra-MT, com a comercialização de toda a produção de um hectare, este preço pagaria o COT, o que demonstra ser a atividade lucrativa no curto prazo. Com índice de lucratividade de 47,41\%, já se teria uma taxa de disponibilidade de receita para a atividade da produção de abóbora, após o pagamento de todas as despesas; e pela margem bruta de $90,16 \%$ do COT, haveria possibilidade de remuneração do risco e da capacidade empresarial do produtor. Por este preço de comercialização da abóbora, com a produção de $1.262 \mathrm{~kg} \cdot \mathrm{ha}^{-1}$, o produtor pagaria todo o COT.

Já para o mercado institucional via PAA de abóbora, utilizado pelo agricultor familiar, o preço médio recebido pela comercialização com o Programa é de $\mathrm{R} \$ 1,08$ por quilograma de abóbora (o valor de comercialização de abóbora pela CPR MT/2014/02/0064 é de R \$1,20, e deste valor a Coopervida retém $10 \%$ ); tem-se, assim, receita bruta de $\mathrm{R} \$ 2.592,00 / \mathrm{ha}$. O lucro operacional foi de $\mathrm{R} \$ 1.329,90 / \mathrm{ha}$, mostrando que a atividade é rentável no curto prazo. O índice de lucratividade é de 51,31\% - isto é, da receita bruta obtida mais da metade é lucro operacional - e com a margem bruta de 105,37\%, vê-se que a lucratividade correspondeu a mais de $100 \%$ do COT. Por este preço de comercialização de abóbora, com a produção de $1.169 \mathrm{~kg} \cdot \mathrm{ha}^{-1}$, o produtor pagaria todo o COT.

Para a cultura da abóbora a variação entre a receita obtida no mercado tradicional e no PAA foi de apenas $8 \%$.

No caso da abóbora, o produtor poderia vender toda a produção de um hectare ao PAA que não atingiria a cota limite de comercialização da modalidade Compra com Doação Simultânea, que para o caso 
No caso da abóbora, o produtor poderia vender toda a produção de um hectare ao PAA que não atingiria a cota limite de comercialização da modalidade Compra com Doação Simultânea, que para o caso de Tangará da Serra-MT, na CPR MT/2014/02/0064 foi de R $\$ 6.500,00$.

E para o caso estudado, seguindo discussões de Grando e Ferreira (2013) e Lopes e Almeida (2012), a comercialização com o PAA, contribui com agricultores familiares que não têm condições de competir em circunstâncias de livre mercado, assim via Programa vendem seus produtos a preços definidos e assim tornam-se menos dependentes da ação dos intermediários e das oscilações excessivas dos preços do mercado varejista, mesmo que não seja um mecanismo de comercialização da produção com ganhos maiores que a comercialização com o mercado tradicional. Todavia, o PAA torna-se um canal alternativo de comercialização, o qual pode possibilitar ao produtor um fortalecimento deste na relação de determinação de preços do produto na comercialização com os intermediários, que inclusive praticam os preços do PAA para tornarem-se viáveis junto a comercialização com os agricultores familiares (DIAS et al., 2013).

\section{CONCLUSÃO}

O cultivo de abóbora em Tangará da Serra-MT, mostra-se como uma atividade viável pelos indicadores dos custos de produção e da análise econômica, tendo-se índices lucratividade que variam de $47,41 \%$ a $51,31 \%$.

A atividade de produção de abóbora possui potencial de geração de renda a agricultores familiares. Tem-se no PAA, um mercado com preços definidos para o ano, fator que possibilita ao produtor maior independência as oscilações e condições do mercado tradicional.

\section{AGRADECIMENTOS}

Ao financiamento da FAPEMAT - Fundação de Amparo à Pesquisa de Mato Grosso pelo Edital Universal Doutor FAPEMAT 003/2014.

\section{REFERÊNCIAS}

AMARO, G. B. et al.Recomendações técnicas para o cultivo de abóbora híbrida do tipo japonesa. Brasília, DF: Embrapa Hortaliças, 2014. (Circular Técnica, n. 137)

ARAÚJO, J. L. P.; CORREA, R. C. Análise dos custos de produção e da rentabilidade do sistema típico de produção de abóbora no Submédio São Francisco. In: CONGRESSO DA SOCIEDADE BRASILEIRA DE SISTEMAS DE PRODUÇÃO, 8., 2010, São Luiz. Anais... Pelotas: SBSP, 2010. p. 1-5. Disponível em: 〈http://www.alice.cnptia.embrapa.br/alice/bitstream/doc/859568/1/lincoln.pdf >. Acesso em: 13 jun. 2016.

BECKER, C.; ANJOS, F. S. Segurança alimentar e desenvolvimento rural: limites e possibilidades de aquisição de alimentos da agricultura familiar, em municípios do Sul gaúcho. Segurança Alimentar e Nutricional, Campinas, v. 17, n. 1, p. 61-72. 2010. Disponível em: $<$ http://periodicos.sbu.unicamp.br/ojs/index.php/san/article/view/8634800/2719>. Acesso em: 13 jun. 2017.

BRASIL. Lei nº 10.696, de 2 de julho de 2003. Dispõe sobre a repactuação e o alongamento de dívidas oriundas de operações de crédito rural, e dá outras providências. Diário Oficial da União, Brasília, DF, 03 de julho de 2003. Disponível em <http://www.conab.gov.br/OlalaCMS/uploads/arquivos/15_12_07_17_25_57_livreto_paa_correta.pdf>. Acesso em: 13 jun. 2016. 
COMPANHIA NACIONAL DE ABASTECIMENTO. Custos de produção agrícola: a metodologia da Conab. Brasília: Conab, 2010. 60 p.

DIAS, T. F.et al. O Programa de Aquisição de Alimentos da Agricultura Familiar (PAA) como estratégia de inserção socioeconômica: o caso do Território da Cidadania Sertão do Apodi (RN). Revista Brasileira de Gestão e Desenvolvimento Regional, Taubaté, v. 9, n.3, p. 100-129, 2013. Disponível em: $<$ https://www.rbgdr.net/revista/index.php/rbgdr/article/view/1127/347>. Acesso em: 10 jun. 2016.

FACHINI, C.et al. Viabilidade econômica das culturas de feijão, abóbora e mandioca para indústria em consórcio com eucalipto, região de Capão Bonito, estado de São Paulo. Informações Econômicas, São Paulo, v. 39, n. 5, p. 16-28. 2009. Disponível em: <http://www.iea.sp.gov.br/ftpiea/publicacoes/IE/2009/t0509.pdf>. Acesso em: 10 jun. 2017.

GRANDO, M. Z.; FERREIRA, G. S. O Programa de Aquisição de Alimentos (PAA) e sua relação com o Rio Grande do Sul. Textos para Discussão FEE n 113. Porto Alegre. 2013. Disponível em: <http://cdn.fee.tche.br/tds/113.pdf >. Acesso em: 08 jun. 2017.

KAGEYAMA, A.; BERGAMASCO, S. M. P. P.; OLIVEIRA, J. T. A. Uma tipologia dos estabelecimentos agropecuários do Brasil a partir do censo de 2006. Revista de Economia e Sociologia Rural, Piracicaba, v. 51, n. 1, p. 105-122, 2013. Disponível em: 〈http://www.scielo.br/pdf/resr/v51n1/06.pdf >. Acesso em: 08 jun. 2017.

LOPES, D. E.; ALMEIDA, R. A. Avaliação do Programa de Aquisição de Alimentos (PAA) e do Programa Nacional de Alimentação Escolar (PNAE) nos municípios de Castilho e Andradina-SP. Pegada, Presidente Prudente, v. 13, n. 1, p. 132-148, 2012. Disponível em: <http://revista.fct.unesp.br/index.php/pegada/article/viewFile/1036/1906>. Acesso em: 08 jun. 2017.

MARCELINO, J. S.; MARCELINO, M. S. Dossiê técnico: cultivo de abóboras. Instituto de Tecnologia do Paraná, 2012. 24 f.

MARTIN, N. B.et al. Sistema integrado de custos agropecuários - CUSTAGRI. Informações Econômicas. São Paulo, v. 28, n. 1, p. 7-28. 1998. Disponível em: 〈http://www.iea.sp.gov.br/ftpiea/ie/1998/tec1-0198.pdf>. Acesso em: 13 jun. 2017.

MATSUNAGA, M. et al. Metodologia de custo de produção utilizada pelo IEA. Agricultura em São Paulo, São Paulo, v. 23, n. 1, p. 123-139, 1976. Disponível em: 〈http://www.iea.sp.gov.br/ftpiea/rea/tomo1_76/artigo3.pdf > . Acesso em: 13 jun. 2017.

MINISTÉRIO DA CIDADANIA - MDS. Programa de Aquisição de Alimentos. Brasília, DF,2019. Disponível em: <http://mds.gov.br/assuntos/seguranca-alimentar/programa-de-aquisicao-de-alimentospaa>. Acesso em: 27 mar. 2019.

RAMOS, S. R. R.et al. Aspectos técnicos do cultivo da abóbora na região Nordeste do Brasil. Aracaju: Embrapa Tabuleiros Costeiros, 2010. 36 p. (Documentos / Embrapa Tabuleiros Costeiros). Disponível em: 〈http://www.cpatc.embrapa.br/publicacoes_2010/doc_154.pdf >. Acesso em: 08 jun. 2016.

RESENDE, G. M.; BORGES, R. M. E.; GONÇALVES, N. P. S. Produtividade da cultura da abóbora em diferentes densidades de plantio no Vale do São Francisco. Horticultura Brasileira, Brasília, DF, v. 31, p. 504-508, 2013. Disponível em: <http://www.scielo.br/pdf/hb/v31n3/27.pdf〉. Acesso em: 23 abr. 2017.

SOUZA, E. G. F.et al. Produção de mudas de cucurbitáceas utilizando esterco ovino na composição de substratos orgânicos. Revista Agro@mbiente On-line, Boa Vista, v. 8, n. 2, p. 175-183, 2014. Disponível em: 〈http://revista.ufrr.br/index.php/agroambiente/article/viewFile/1675/1321 >. Acesso em: 08 jun. 2017. 